\title{
Pattern of Head Injuries in Deaths Due to Two-Wheeler Road Traffic Accidents
}

\author{
S.M. Krishna Sagar ${ }^{1}$, Divya Reddy Pannala ${ }^{2}$, K.V. Ramanamurthy ${ }^{3}$, K. Rajender Kumar ${ }^{4}$ \\ ${ }^{1}$ Assistant Professor, Department of Forensic Medicine, Mahavir Institute of Medical Sciences, Vikarabad, \\ ${ }^{2}$ Assistant Professor, Department of Forensic Medicine, RVM Institute of Medical Sciences, Siddipet, ${ }^{3}$ Professor, \\ Department of Forensic Medicine, Osmania Medical College, Hyderabad, ${ }^{4}$ Professor \& Head, Department of \\ Forensic Medicine, Gandhi Medical College, Secunderabad
}

\begin{abstract}
Background: In India, from the past two decades, along with urbanization, industrialization, population explosion and migration of people, there has also been rapid growth in the field of road transportation. Cons of this can be seen in the form of increased deaths due to RTA.

Method: We conducted a cross sectional studyin department of forensic medicine, Gandhi Medical College, Hyderabad including all cases of accidental deaths due to two-wheeler, aged above 6 years between October 2014 to May 2016.

Results: Majority cases were in the age group of 21-30 years, 27 (25.7\%) and males 89(84.8\%). Majority victims encountered accident due to skid $40(38.1 \%)$ and head on collision being common 50(47.6\%). Linear fracture of vault was found in almost half cases, 53(50.5\%). Subdural and subarachnoid haemorrhage were the most common one we encountered.

Conclusions: Males in productive age group encountered fatal RTA and also linear fracture, SDH and SAH were common pattern of injury seen in them. Stringent laws and awareness have to be created to reduce the fatalities.
\end{abstract}

Keywords: Head injury, road traffic accident, two-wheeler, skull fracture, intra cranial haemorrhage.

\section{Introduction}

Road traffic accidents have become a growing health and development problem. Approximately 1.35 million people die each year because of road traffic crashes in the world. More than $90 \%$ of road traffic deaths occur in low and middle income countries. ${ }^{1}$

In India, the increase in motorization along with expansion of the road network has brought not only rural economic development but also some adverse effects

\footnotetext{
Corresponding Author:

Dr. Divya Reddy Pannala

Assistant Professor, Department of Forensic Medicine, RVM Institute of Medical Sciences, Siddipet

e-mail: divyarpannala@gmail.com

Mobile Number: 9966253961
}

such as the increase in road accidents and among them most common are two wheelers as they constitute main vehicle fleet. $^{2}$

RTA are likely to be seen in the age group 15-44 years and the usual causative factors being defective vehicle, due to defective rider and due to defective environment. ${ }^{2,3}$

The most prominent and vulnerable part of human body is head which made it more vulnerable for injury in road traffic accidents. ${ }^{2}$ The most common cause of TBI normally reported in our country are road traffic accidents (RTA) accounting for $60 \%$, followed by falls and assaults contributing to $25 \%$ and $10 \%$ of traumatic brain injuries, respectively. ${ }^{4}$

Head injury has been defined as "a morbid state, resulting from gross or subtle structural changes in the 
scalp, skull and/or the contents of skull, produced by mechanical forces. It has also been defined as physical damage to the scalp, skull or brain produced by an external force however, such force/impact, responsible for the injury need not be applied directly to the head. ${ }^{5}$

Thus, the study was taken up to determine the pattern of head injuries in people died due to accidents involving two wheelers which are subjected to postmortem examinations along with the socio demographic factors of the victims

\section{Method}

This was a cross sectional study done in Forensic Medicine department of Gandhi Medical College and Hospital, Secunderabad. The study included all cases of accidental deaths due to two wheeler road traffic accidents which were admitted in Gandhi hospital and died eventually and also spot deaths which were directly brought to mortuary for post mortem examination over a study period of 2 years (October 2014- May 2016). Both rider and pillion rider who died due to head injuries with history of two wheeler road traffic accidents and aged above 6 years were included in the study and cases whose deaths occurred due to other vehicles and pedestrian deaths due to two wheelers were excluded. Socio demographic variables and details about manner of death were obtained from reliable attendants of the deceased, hospital records, police records and inquest reports submitted with autopsy requisition in each case by concerned police officers. Other details from the postmortem examination and reports. The family members, relatives and friends were fully explained about the questionnaire and then verbal consent was taken from each individual before asking about the relevant details pertaining to the study and thus a total of 105 cases were analysed.

Statistical analysis: Data was analysed using SPSS software and descriptive analysis was done. Data were presented in the form of tables, text, and figures.

\section{Results}

The mean age of the cases included in the study was $38.17 \pm 15.15$ years. The cases mostly belonged to age group 21-30 (25.7\%) followed by $31-40$ years $(23.8 \%)$, $41-50$ years $(18.1 \%), 51-60$ years $16(15.2 \%), 11-20$ years $9(8.5 \%), 61-70$ years $5(4.7 \%),>70$ years $3(2.8 \%)$ and $<10$ years $1(0.95 \%)$. Males comprised a majority of cases and constituted $89(84.8 \%)$ compared to females which was $16(15.2 \%)$.Considering geographical distribution of cases, $77(73.3 \%)$ were from rural area and $28(26.7 \%)$ from urban area. Nearly half of them belonged to lower socio-economic status $48(45.7 \%)$ followed by middle class, $42(40 \%)$ and upper class $15(14.3 \%)$.

Table 1 Characteristics of vehicle and related variables

\begin{tabular}{|l|l|c|c|}
\hline \multicolumn{2}{|l|}{ Variable } & Number (n) & Percentage (\%) \\
\hline \multirow{2}{*}{$\begin{array}{l}\text { Vehicle used by case during the } \\
\text { time of accident }\end{array}$} & With gear & 75 & $71.4 \%$ \\
\cline { 2 - 4 } & Without gear & 30 & $28.5 \%$ \\
\hline \multirow{3}{*}{ Rider/Pillon rider } & Rider & 94 & $89.5 \%$ \\
\cline { 2 - 4 } & Pillion rider & 11 & $10.5 \%$ \\
\hline \multirow{4}{*}{ Hit by type of vehicle } & Two-wheeler & 27 & $25.7 \%$ \\
\cline { 2 - 4 } & Four-wheeler & 20 & $19.1 \%$ \\
\cline { 2 - 4 } & Heavy vehicle & 18 & $17.2 \%$ \\
\cline { 2 - 4 } & Self-fall & 40 & $38.1 \%$ \\
\hline \multirow{3}{*}{ Type of collision during accident } & Head on & 50 & $47.6 \%$ \\
\cline { 2 - 4 } & Rear end & 20 & $19 \%$ \\
\cline { 2 - 4 } & Self-skid & 35 & $33.3 \%$ \\
\hline
\end{tabular}

In this study most of the cases used with gear vehicles, 75(71.4\%) and were riding 94(89.5\%) them at the time of accident. The major cause of accident was self-fall, 40(38.1\%) due to skid and when accident was due to vehicle, then it was mostly two-wheeler, 27 $(25.7 \%)$ and the collision was head on,50 (47.6\%). 
Table 2 Type of skull fracture due to head injury

\begin{tabular}{|l|c|c|}
\hline Variable & Number (n) & Percentage (\%) \\
\hline Linear & 53 & $50.5 \%$ \\
\hline Depressed & 9 & $8.6 \%$ \\
\hline Compressed & 8 & $7.6 \%$ \\
\hline Crush & 3 & $2.9 \%$ \\
\hline Compressed \& depressed & 8 & $7.6 \%$ \\
\hline Linear \& compressed & 1 & $1.0 \%$ \\
\hline Operated & 7 & $6.7 \%$ \\
\hline Nil & 16 & $15.2 \%$ \\
\hline
\end{tabular}

Table 3 Pattern of head injury

\begin{tabular}{|l|c|c|c|}
\hline \multicolumn{2}{|c|}{ Variable } & Number (n) & Percentage (\%) \\
\hline \multirow{3}{*}{ Contusion } & Yes & 88 & $83.8 \%$ \\
\cline { 2 - 4 } & No & 17 & $16.2 \%$ \\
\hline \multirow{3}{*}{ Laceration } & Yes & 45 & $42.9 \%$ \\
\cline { 2 - 4 } & No & 60 & $57.1 \%$ \\
\hline \multirow{3}{*}{ Abrasion } & Yes & 54 & $51.4 \%$ \\
\cline { 2 - 4 } & No & 51 & $48.6 \%$ \\
\hline
\end{tabular}

Linear fracture, 53(50.5\%) was the most common type of skull fracture and temporal bone was most involved. Contusion, $88(83.8 \%)$ was the commonest injury and in $70 \%$ of cases there were other associated injuries involving other parts of body. Among the intracranial haemorrhages, a combination of $\mathrm{SDH}$ and SAH accounted for $42(40 \%)$ cases followed by combination of SAH and ICH 20 (19\%) cases and SDH alone accounting for $16(15 \%)$ cases, 7 (6.6\%) cases were SAH, 4(3.8\%) ICH, 2 (1.9\%) EDH and rest of the cases, there were multiple combination of intracranial lesions.

[Depicted in Table-2,3 and Figure-1,2]

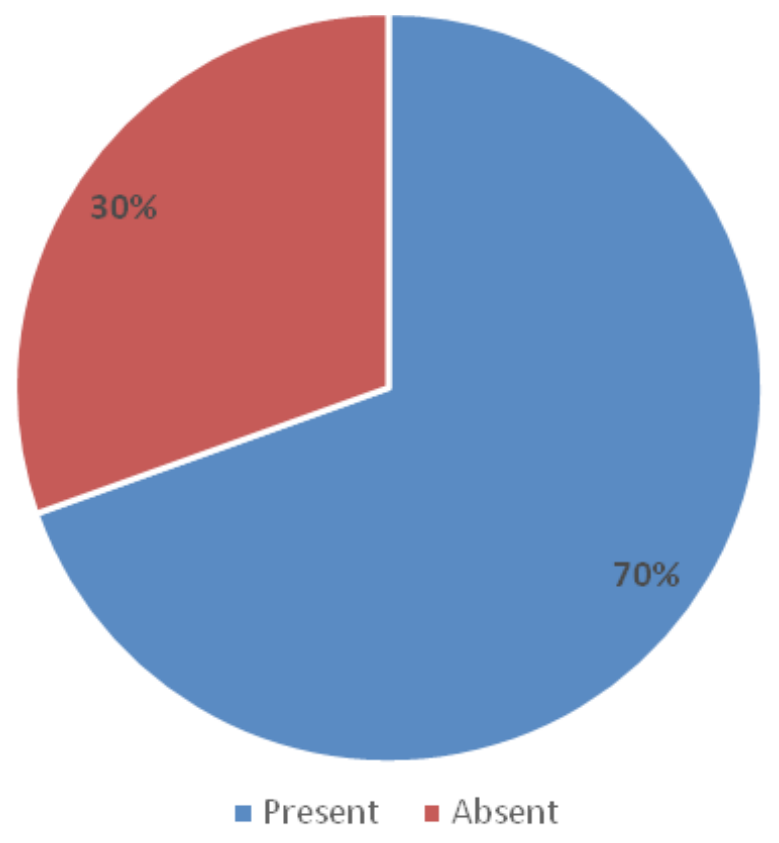

Figure-1 Associated injuries along with head injury

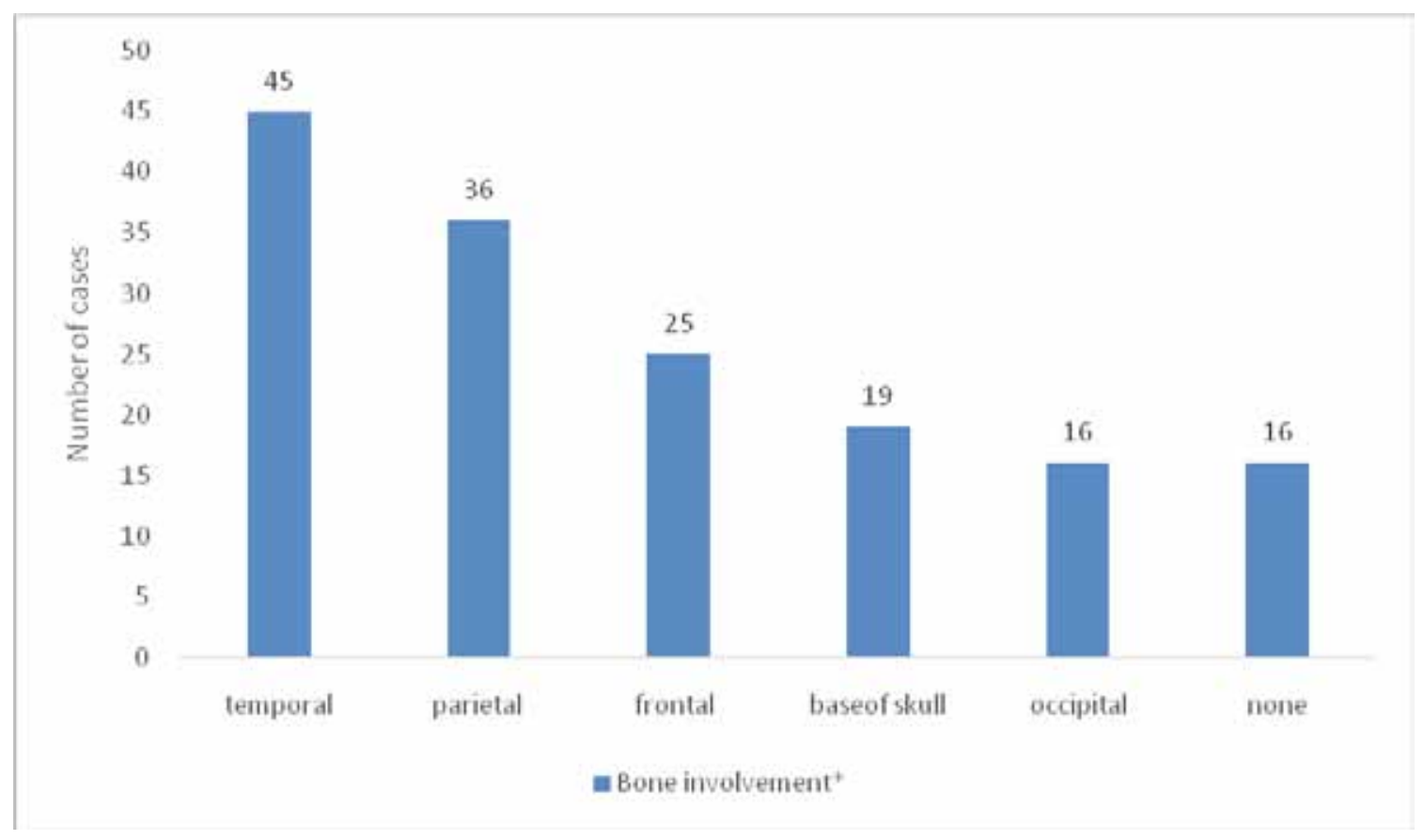

Figure-2 Bone involved in skull fracture (multiple answers) 


\section{Discussion}

This was a two-year study taken up in the forensic department of a tertiary care centre, Gandhi Medical college, Hyderabad, Telangana, India.

In this study, the cases mostly belonged to age group $21-30(25.7 \%)$ followed by $31-40$ years $(23.8 \%)$,similar findings were seen in Mallikarjuna SK et al. ${ }^{6}$ study where as in the study done by Amir et al. ${ }^{7}, 29.8 \%$ were in the age group $30-39$ years and $27.6 \%$ were in the age group 20-29 years.

Males comprised a majority of cases and constituted $84.8 \%$ compared to females which was $15.2 \%$. The male to female ratio in the present study is 5.6: 1 indicating male preponderance, which is similar to the study done by Menon et al. ${ }^{8}$ and Amir et al. ${ }^{7}$

The cases were mostly from rural area $(73.3 \%)$ and majority of them belonged to lower socio-economic status (45.7\%) and middle class (40\%), while the study done by Ranjana Singh et al. ${ }^{9}$ showed that urban cases (64\%) outnumbered rural(36\%).Likewise, according to WHO, more RTA fatalities in India were among low socio-economic groups. ${ }^{9}$

In this study most of the cases used with-gear vehicles, $71.4 \%$ similar to study done by Lohith Naik et al. ${ }^{10}$.More than $2 / 3 \mathrm{rd}$ of the cases, $89.5 \%$ were riding vehicle at the time of accident as seen even in the study done by M. Seethalakshmi et al. ${ }^{11}$. The major cause of accident was self-fall which $38.1 \%$, reason being skid and when accident was due to vehicle collision, it was mostly two-wheeler, $25.7 \%$ and the collision was head on, $47.6 \%$ where as in study done by M. Seethalakshmi et al. ${ }^{11}$,it was collision with light motor vehicle.

In this study, linear fracture, $50.5 \%$ was the most common type of skull fracture and temporal bone was most involved. Contusion, $83.8 \%$ was the commonest injury and in $70 \%$ of cases there were other associated injuries involving other parts of body. Similar findings were seen in the study by M. Seethalakshmi et al. 11, where tempero-parietal region was the most common region involved in fracture and among injuries, $42.8 \%$ were abrasions. $68 \%$ were contusions and $34 \%$ were lacerations and more than $70 \%$ cases had associated injuries involving other parts of body.

Like wise, in a study done by Pathak et al.12 most of the victims of fatal head injury were having linear fracture of either skull vault or base of the skull or both which was $43 \%$, especially in the thin areas of temporo-parietal bone. Another study by Rajeshwar et al.2 also reiterated the findings our study and showed that majority of victims who died from head injury had association with injuries to thoraco-abdominal area and extremities which was $50.64 \%$ of total cases and only $15.86 \%$ deceased showed head injury without any other associated injuries.

Among the intracranial lesions, a combination of SDH and SAH accounted for $40 \%$ cases followed by combination of SAH and ICH $19 \%$ cases and SDH alone accounting for $15 \%$ cases, $6.6 \%$ cases were $\mathrm{SAH}$, $3.8 \% \mathrm{ICH}, 1.9 \% \mathrm{EDH}$ and rest in rest of the cases there were multiple combination of intracranial haemorrhage. Similar findings were seen in the study by Amir et al.7 where intra cranial haemorrhage was seen in $85.9 \%$ of cases and of all bleeds SAH accounted for $55.8 \%$. Even in studies conducted by Pathak et al.12 and Rajeshwar et al $2 \mathrm{SAH}$ and SDH were the common type of bleeds among intra cranial haemorrhage.

\section{Conclusion}

This study reveals that fatalities due to RTA are remarkably high in productive (21-40) year age group, and most victims are males belonging to rural area and low socio-economic class. Linear fracture involving temporal bone and SAH were also common. Road safety awareness programs must be regularly conducted to bring awareness amongst adults. Strict laws, compulsion of helmet usage for both rider and pillion rider and behaviour change communication activities may be game changer in prevention of such high fatalities.

Further study has to be conducted on the factors involved in RTA which may help in better understanding of the situation.

Ethical Clearance: Taken from the Institutional Ethical Committee of the medical college.

\section{Conflict of Interest: Nil}

\section{Source of Funding: Nil}

\section{References}

1. WHO. Road traffic injuries. Fact sheet . World Health Organization. [online] [Last accessed on 2020 June 24]. Available from: https://www. who.int/news-room/fact-sheets/detail/road-trafficinjuries. 
2. Pate RS, Hire RC, Rojekar MV. Pattern of head injury in central India population. International Journal of Research in Medical Sciences. 2017 Aug;5(8):3515-9.

3. Pal R, Ghosh A, Kumar R, Galwankar S, Paul SK, Pal S, Sinha D, Jaiswal AK, Moscote-Salazar LR, Agrawal A. Public health crisis of road traffic accidents in India: Risk factor assessment and recommendations on prevention on the behalf of the Academy of Family Physicians of India. Journal of family medicine and primary care. 2019 Mar;8(3):775.

4. Agrawal A, Munivenkatappa A, Shukla DP, Menon GR, Alogolu R, Galwankar S, Kumar SS, Momhan PR, Pal R, Rustagi N. Traumatic brain injury related research in India: An overview of published literature. International journal of critical illness and injury science. 2016 Apr;6(2):65.

5. American College of. Surgeons Committee on trauma. Resources for the optimal care of the injured patient, Chicago III. American College of Surgeons 1993.

6. Mallikarjuna SK, Krishnappa P. Prevalence of maxillofacial injuries by motorized two wheeler road traffic accidents in Bangalore city. Dent Traumatol. 2009 Dec;25(6):599-604. doi: 10.1111/j.1600-9657.2009.00832.x.Epub 2009 Oct 14.
7. Amir A, Hoda MF, Khalil S, Kirmani S. Pattern of head injuries among victims of road traffic accidents in a tertiary care teaching hospital. Indian Journal of Community Health. 2013 Jun 30;25(2):126-33.

8. Menon A, Pai VK, Rajeev A. Pattern of fatal head injuries due to vehicular accidents in Mangalore. J Forensic Leg Med. 2008 Feb;15(2):75-7. doi:10.1016/j.jflm.2007.06.001. Epub 2007 Sep 27.

9. WHO. Road traffic injuries. Fact sheet No. 358. World Health Organization. [online] [Last accessed on 2020 May 2020]. Available from: http://www. who.int/news-room/fact-sheets/detail/road-trafficinjuries .

10. Naik L, Kainoor S, Sangram R, Neeta PN. Epidemiological study of two wheeler traffic accident victims in medicolegal autopsies. IJFMTS. 2016 Oct;1(1):11-3.

11. Seethalakshmi M, Sudalaimuthu R, Mahendran J, Nagendrakumar A. Study of injury pattern in human beings in road traffic accidents involving two wheelers. Journal of Evolution of Medical and Dental Sciences. 2015 Sep 24;4(77):13436-59.

12. AkhileshPathak, N.L. Desania and Rajesh Verma. Profile of road traffic accidents and Head Injury in Jaipur (Rajasthan).J. Indian Acad Forensic Med, $30(1)$. 